\title{
Autosomal recessive bestrophinopathy
}

INSERM

\section{Source}

INSERM. (1999). Orphanet: an online rare disease and orphan drug data base. Autosomal recessive bestrophinopathy. ORPHA:139455

Autosomal recessive bestrophinopathy (ARB) is a retinal dystrophy, characterized by central visual loss in the first 2 decades of life, associated with an absent electrooculog ram (EOG) light rise and a reduced electroretinogram (ERG). 